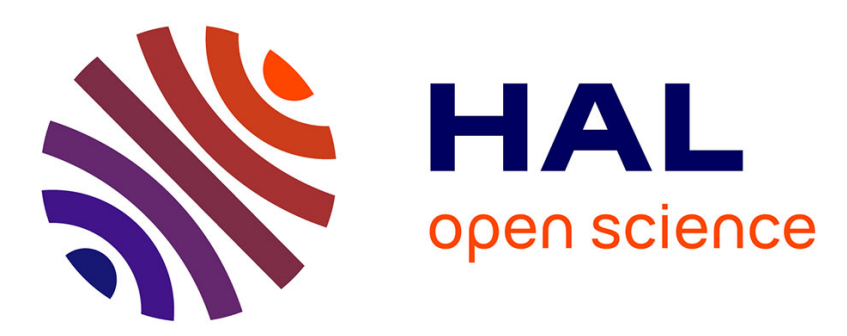

\title{
Inbreeding in mid-rotation coastal Douglas-fir: implications for breeding
}

Michael Stoehr, Peter Ott, Jack Woods

\section{To cite this version:}

Michael Stoehr, Peter Ott, Jack Woods. Inbreeding in mid-rotation coastal Douglas-fir: implications for breeding. Annals of Forest Science, 2015, 72 (2), pp.195-204. 10.1007/s13595-014-0414-0 . hal01284166

\section{HAL Id: hal-01284166 \\ https://hal.science/hal-01284166}

Submitted on 7 Mar 2016

HAL is a multi-disciplinary open access archive for the deposit and dissemination of scientific research documents, whether they are published or not. The documents may come from teaching and research institutions in France or abroad, or from public or private research centers.
L'archive ouverte pluridisciplinaire HAL, est destinée au dépôt et à la diffusion de documents scientifiques de niveau recherche, publiés ou non, émanant des établissements d'enseignement et de recherche français ou étrangers, des laboratoires publics ou privés. 


\title{
Inbreeding in mid-rotation coastal Douglas-fir: implications for breeding
}

\author{
Michael Stoehr • Peter Ott • Jack Woods
}

Received: 26 November 2013 / Accepted: 11 July 2014 / Published online: 1 August 2014

(C) INRA and Springer-Verlag France 2014

\begin{abstract}
- Context The effects of inbreeding on growth traits have been studied and are fairly well understood in young conifers. However, in trees approaching mid-rotation, this information is not widely available at present.

- Aim The aim of this study is to assess inbreeding depression in mid-rotation coastal Douglas-fir in growth traits, survival, and wood density.

- Methods Several levels of inbreeding were created in coastal Douglas-fir, using a nine-clone founder population to produce 148 families with varying levels of inbreeding ranging from $f=0$ (outcrossed) to $f=0.5$ (selfed). The trees were planted in 1987 on two farm-field sites in coastal BC. Here, we report effects of inbreeding in height, diameter, tree volume, survival, and wood density in 26-year-old trees.

- Results Previous results obtained from this test population showed negative near linear effects with levels of inbreeding in seed production, nursery growth performance, and growth
\end{abstract}

Handling Editor: Bruno Fady

Contribution of the co-authors Michael Stoehr was responsible for data collection, analysis, and interpretation of the results. Peter Ott was instrumental in developing the linear models and matrix notation in the paper. Jack Woods initially conceived the idea of the experiment, designed and established the inbreeding trial, and contributed to the writing of the paper.

M. Stoehr $(\bowtie)$

Tree Improvement Branch, BC Ministry of Forests, Lands and Natural Resource Operations, Saanich Seed Orchard, 7380 Puckle

Road, Saanichton, BC V8M 1W4, Canada

e-mail: Michael.Stoehr@gov.bc.ca

P. Ott

Forest Analysis and Inventory Branch, BC Ministry of Forests, Lands and Natural Resource Operations, Victoria, BC, Canada

J. Woods

SelectSeed Ltd., Vancouver, BC, Canada traits in the field assessed at age 10. At age 26, inbreeding depression was highest in survival, ranging from 20 to $80 \%$ for $f=0.125$ and $f=0.5$, respectively. In contrast, the most severe inbreeding depression among the three levels of inbreeding was only $4 \%$ for wood density at $f=0.5$ (selfing). Inbreeding depression in height, diameter at breast height (dbh), and volume increased linearly from $f=0$ to $f=0.25$, then leveled off.

- Conclusion Founder genotypes had varied responses to inbreeding as parental breeding values across inbreeding levels were inconsistent (in magnitude, sign, and trait). No differences in levels of inbreeding depression were found between full-sib matings and parent-offspring matings. These findings have implications for the testing of parents within sublines, where inbreeding is accumulated in sublines. However, since parents respond differently to levels of inbreeding, their performance may not be well correlated to their quality as outcrossing parents.

Keywords Progeny testing $\cdot$ Pseudotsuga menziesii . Selfing $\cdot$ Parent-offspring mating

\section{Introduction}

Most conifers have a mixed mating system with outcrossing facilitated by wind pollination as the predominant mating type. Selfing and mating among relatives are possible as there are no complete zygotic incompatibilities against these mating types. The presence of embryonic lethals in their homozygous state reduces the effective selfing rate, but this preventative measure is not infallible and selfed progeny can establish through natural regeneration. Several studies have shown the deleterious effects of selfing on seedling 
vigor, seed set, and survival (Sorensen 1999; Woods and Heaman 1989; Wang et al. 2004). The severity of inbreeding is commonly expressed as inbreeding depression (ID), which is the relative difference in performance of inbred to outcrossed progeny. Matings producing lower levels of inbreeding (sib and/or parentoffspring matings) generally result in less severe ID. Growth performance (height, diameter, and volume per tree) and survival are traits most affected by inbreeding, while wood property traits show much less ID. The precise genetic basis of ID in conifers has not been elucidated yet (Williams and Savolainen 1996), but the most likely explanation is partial dominance of deleterious recessive alleles due to increased levels of homozygosity caused by inbreeding (Charlesworth and Charlesworth 1987). However, it is becoming clear that the mutated recessive alleles (deleterious mutations) are maintained in the population at low frequencies despite constantly being selected against (mutation-selection balance) (Charlesworth and Willis 2009). Recently, an epigenetic effect, mediated through increased DNA methylation in inbred plants of the perennial Scabiosa columbaria, has been implicated (Vergeer et al. 2012).

In coastal Douglas-fir (Pseudotsuga menziesii (Mirb.) Franco), the early inbreeding studies of Orr-Ewing (1954, 1957) showed ID in the seed set of cone-bearing trees and height growth of trees that were dwarves and never produced any strobili (Orr-Ewing 1976). Our knowledge of inbreeding effects has been greatly advanced by Sorensen's work with Douglas-fir (and other conifers), showing that growth and survival had high ID, upwards of $80 \%$. More recently, Woods et al. (2004) showed that growth reduction was nearly linear with the level of inbreeding. A reduction of roughly $10 \%$ in growth was observed for every 0.1 increase in $f$ (inbreeding coefficient). A large range in the response to inbreeding of individual trees has been observed (Sorensen and Miles 1974, 1982).

While it is well established that growth traits and survival suffer the most from inbreeding, wood characteristics exhibit much less ID. It is assumed that the genetic load (as recessive lethals or deleterious homozygotes) for those non-fitness traits is much lower. The work in Pinus radiata and Pinus taeda clearly demonstrates that wood density is not affected by inbreeding (Wu et al. 2002; Ford 2012).

In this paper, we are specifically interested in inbreeding depression in growth traits, survival, and wood density as test trees approach mid-rotation using an experiment established by Woods and Heaman (1989). We know that Douglas-fir is sensitive to inbreeding and as a result can suffer from dwarfism and a lack of gamete production (Orr-Ewing 1974, 1976). We therefore, hypothesize that inbreeding depression continues to purge inbred genotypes as competition becomes more intense as the test plantations develop to maturity.

\section{Materials and methods}

\subsection{Seedling propagation and plantation establishment}

A nine-parent founder population of unrelated coastal Douglasfir trees was used in a $5 \times 4$ factorial to create 20 non-inbred (outcrossed) families, 66 families resulting from half-sib matings, 36 families resulting from full-sib crosses, 17 parent-offspring families, and nine families resulting from selfing, representing inbreeding levels of $f=0.0,0.125,0.25$, and 0.5 , respectively. Controlled sib matings (including parent-offspring matings) were made in a full-sib progeny test where the original nine founders were parents. Details of the matings can be found in Woods and Heaman (1989). Seedlings were raised in 1987 in 415A styroblocks having 80 cavities $\left(130 \mathrm{~cm}^{3}\right.$ cavity volume, $15-\mathrm{cm}$ depth) at Cowichan Lake Research Station under standard growing conditions for commercially grown and planted coastal Douglas-fir. After lifting in the fall, all seedlings were subjected to standard culling procedures and only seedlings passing the culling standards were subsequently planted. Due to higher culling rates of seedlings with higher levels of inbreeding (Table 1), this likely resulted in a stronger selection against poor growth in families with higher $f$ values. The intent, however, was to plant and assess only seedlings that would not be culled from nursery stock under normal operational conditions (Woods et al. 2002).

Seedlings were planted in May 1988 on two farm-field sites in coastal British Columbia (North Arm $\left(48^{\circ} 49^{\prime} \mathrm{N}\right.$, $124^{\circ} 20^{\prime} \mathrm{W}$ ) and Langley $\left(49^{\circ} 06^{\prime} \mathrm{N}, 122^{\circ} 38^{\prime} \mathrm{W}\right)$ ). Each site was set up as a one-way randomized complete block design (with subsampling) with family (all 148) as the experimental factor. Specifically, seedlings were planted in single-tree plots in four interlocking subsamples within eight complete blocks (Wang et al. 2004). Thus, each family was represented by 32 seedlings per site. Seedlings were planted at $1.0 \times 1.0 \mathrm{~m}$ spacing at Cowichan and at $1.5 \times 1.0 \mathrm{~m}$ at Langley.

\subsection{Measurements and data analysis}

Total heights were measured at age 2, 6, 10, and 26 years from seed. Diameter at the root collar was measured at age six and at breast height (dbh) at ages 10 and 26. For the age 26 measurements, trees in only four randomly chosen blocks per site were measured. Volume was calculated as follows: $\operatorname{Vol}\left[\mathrm{m}^{3}\right]=e^{a} \mathrm{dbh}[\mathrm{cm}]^{b} \mathrm{ht}[\mathrm{m}]^{c}$ where $a=-9.8963$ $25907, b=1.83478844$, and $c=1.00511916$ (Omule et al. 1987). In addition, on trees with a dbh of $>4.6 \mathrm{~cm}$, a 1$\mathrm{cm}$ increment core from bark to bark was taken at $1.3 \mathrm{~m}$ (in a north-south direction). Increment cores were used to determine wood density according to Smith (1954). Survival was calculated as a percentage of trees living over the number of trees planted. Inbreeding depression (ID) for each variable was 
Table 1 Means (standard deviations) for traits measured in four levels of inbreeding and two ages (10 and 26 years) in coastal Douglas-fir planted on two sites in southern British Columbia

Site Inbreeding Number Culling (\%) $\quad$ Survival (\%) Height $10(\mathrm{~m})$ Height $26(\mathrm{~m})$ Diameter $26(\mathrm{~cm})$ Volume $26\left(\mathrm{~m}^{3}\right) \quad$ Wood density 26 level $(f)$

\begin{tabular}{llllllllll}
\hline Langley & 0 & 200 & 5 & 63 & $5.5(0.9)$ & $13.9(2.2)$ & $11.2(4.2)$ & $0.07(0.06)$ & $0.501(0.028)$ \\
& 0.125 & 441 & 10 & 40 & $5.2(0.9)$ & $13.1(2.4)$ & $9.8(3.6)$ & $0.05(0.05)$ & $0.496(0.027)$ \\
& 0.25 & 204 & 10 & 24 & $5.1(0.9)$ & $13.0(2.1)$ & $9.6(3.3)$ & $0.05(0.04)$ & $0.497(0.026)$ \\
& 0.5 & 7 & 15 & 10 & $5.5(1.2)$ & $13.2(2.5)$ & $10.8(4.7)$ & $0.07(0.07)$ & $0.484(0.016)$ \\
North Arm & 0 & 306 & 5 & 95 & $5.2(1.2)$ & $16.3(2.5)$ & $14.1(3.5)$ & $0.12(0.06)$ & $0.458(0.025)$ \\
& 0.125 & 935 & 10 & 86 & $4.8(1.2)$ & $14.9(2.8)$ & $12.0(3.5)$ & $0.08(0.06)$ & $0.452(0.027)$ \\
& 0.25 & 590 & 10 & 68 & $4.5(1.3)$ & $13.5(2.9)$ & $10.3(3.2)$ & $0.06(0.04)$ & $0.458(0.029)$ \\
& 0.5 & 16 & 15 & 16 & $4.4(1.3)$ & $12.6(3.8)$ & $9.6(3.9)$ & $0.05(0.05)$ & $0.441(0.022)$ \\
\hline
\end{tabular}

${ }^{\text {a }}$ Seedlings prior to planting were culled according to culling standard 2 (minimum/maximum height $15 / 30 \mathrm{~cm}$ and $3 / 3.5 \mathrm{~mm}$ diameter) resulting of all planted seedlings to be of similar size (Woods et al. 2002)

calculated as the percentage deviation from outcross means for each level of inbreeding (Burdon and Russell 1998):

$\mathrm{ID}=100 \cdot(1-I / O)$

where $I$ and $O$ are the means for the various inbred and outcross groups.

To calculate genetic variation in individual tree height, dbh, and calculated volume at a given year, observations were modeled using a linear mixed-effects family model:

$\boldsymbol{y}=\mathbf{X} \boldsymbol{b}+\mathbf{Z u}+\boldsymbol{e}$

where $\boldsymbol{y}$ is the $n \times 1$ dependent variable vector (e.g., height, dbh, volume, etc.), with $n \cong 4,736$ trees, $\boldsymbol{e}$ is the $n \times 1$ vector of residual errors (represented by individual trees), $\mathbf{X}_{n} \times 5$ and $\mathbf{Z}_{n \times 1,636}$ are simple design matrices for the fixed and random effects consisting of $1 \mathrm{~s}$ and $0 \mathrm{~s} . \boldsymbol{b}^{\prime}=\left[\boldsymbol{b}_{\mathbf{1}} \mid \boldsymbol{b}_{\mathbf{2}}\right]$ describes the two fixed effects: $\boldsymbol{b}_{\mathbf{1}}=\left[\begin{array}{ll}\mu & s_{1}\end{array}\right]$ (site) and $\boldsymbol{b}_{\mathbf{2}}=\left[\begin{array}{lll}l_{1} & l_{2} & l_{3}\end{array}\right]$ (inbreeding level, $f=0,0.125,0.25$, or 0.5$) . \boldsymbol{u}^{\prime}=\left[\boldsymbol{u}_{\mathbf{1}}\left|\boldsymbol{u}_{\mathbf{2}}\right| \boldsymbol{u}_{\mathbf{3}} \mid \boldsymbol{u}_{\mathbf{4}}\right]$ describes the four random effects: $\boldsymbol{u}_{\mathbf{1}}=\left[\begin{array}{lllll}s_{1} b_{1} & s_{1} b_{2} \ldots s_{1} b_{4} & s_{2} b_{1} & s_{2} b_{2} \ldots\end{array}\right.$

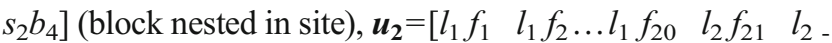
$\left.f_{22} \ldots l_{2} f_{86}, \ldots, l_{4} f_{139} l_{4} f_{140} \ldots l_{4} f_{148}\right]$ (family nested in level), $\boldsymbol{u}_{\mathbf{3}}=\left[\begin{array}{lllll}s_{1} f_{1} & s_{1} f_{2} \ldots s_{1} f_{148} & s_{2} f_{1} & s_{2} f_{2} \ldots s_{2} f_{148}\end{array}\right]$ (interaction of

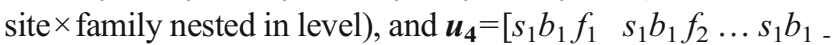

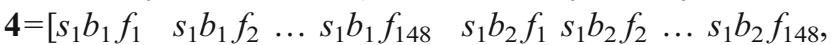
$\left.\ldots, s_{2} b_{4} f_{1} s_{2} b_{4} f_{2} \ldots s_{2} b_{4} f_{148}\right]$ (interaction of block nested in site $\times$ family nested in level).

Random effects are assumed to be mutually independent and normally distributed with mean 0 and the following basic covariance structure (Costa e Silva et al. 2001): $\left[\begin{array}{l}u \\ e\end{array}\right] \sim N\left(\left[\begin{array}{l}\mathbf{0} \\ \mathbf{0}\end{array}\right],\left[\begin{array}{cc}\mathbf{G} & \mathbf{0} \\ \mathbf{0} & \mathbf{R}\end{array}\right]\right)$, where

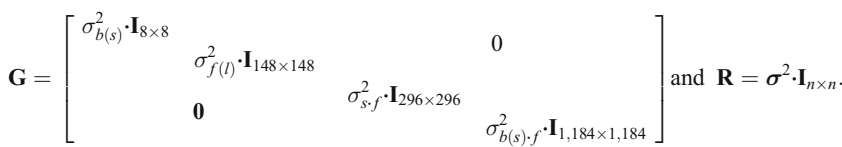

Wood density and height have a known negative genetic correlation in Douglas-fir (Ukrainetz et al. 2008; El-Kassaby et al. 2011). Therefore we had to first determine if inbreeding directly causes differences in wood density or indirectly through a reduction in height growth. If regression lines between wd and height for each level of $f$ are parallel, then, wood density does not need to be adjusted for differences in height growth. To check, we added covariates height and inbreeding level $\times$ height to model (1). A non-significant height $\times$ inbreeding interaction indicates that the linear relationship between wood density and height is parallel among levels of inbreeding, and wood density means can be compared directly via ANOVA according to the original model (1).

Significance testing of the variance component for the family site interaction $\sigma_{s f}^{2}$ for each trait was done as outlined by Dutkowski et al. (2002), using the likelihood ratio test (LRT) by differencing twice the fitted residual log likelihoods with and without the interaction term. The test statistics were compared with a 50:50 mixture of chi-square distributions with 3 and $4^{\circ}$ of freedom (Verbeke and Mohlenbergs 2000).

To estimate breeding values (bv) for founder parents for the various inbreeding levels, an individual tree model was fitted separately to data from each level of $f$ (with the exception of $f=0.5$ as the number of surviving trees was too low). It is similar to model (1) but without the fixed inbreeding level effect, the addition of an additive genetic effect for the individual seedlings, and a more complex covariance structure for $\boldsymbol{G}$. In particular, $\boldsymbol{b}^{\prime}=\left[\begin{array}{ll}\mu & s_{1}\end{array}\right]$ describes the fixed effect for site, $\boldsymbol{u}$ '=[ $\left[\begin{array}{l|l|l|l|l}\boldsymbol{u}_{\mathbf{1}} & \boldsymbol{u}_{\mathbf{2}} & \boldsymbol{u}_{\mathbf{3}} & \boldsymbol{u}_{\mathbf{4}} & \boldsymbol{u}_{\mathbf{5}}\end{array}\right]$ describes the five random effects: $\boldsymbol{u}_{\mathbf{1}}=\left[\begin{array}{lll}s_{1} b_{1} & s_{1} b_{2} \ldots s_{1} b_{4} s_{2} b_{1} s_{2} b_{2} \ldots s_{2} b_{4}\end{array}\right]$ (block nested in site), $\boldsymbol{u}_{\mathbf{2}}=\left[\begin{array}{lll}f_{1} & f_{2} \ldots f_{m}\end{array}\right]$ (family) where $m$ denotes the number of families for that particular level of $f$ (e.g., $m=20$ outcrossed families), $\boldsymbol{u}_{\mathbf{3}}=\left[\begin{array}{lllll}s_{1} f_{1} & s_{1} f_{2} \ldots s_{1} f_{m} & s_{2} f_{1} & s_{2} f_{2} \ldots s_{2} f_{m}\end{array}\right]$ (interaction 


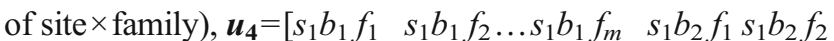
$\left.\ldots s_{1} b_{2} f_{m}, \ldots, s_{2} b_{4} f_{1} s_{2} b_{4} f_{2} \ldots s_{2} b_{4} f_{m}\right]$ (interaction of block nested in site $\times$ family), and $\boldsymbol{u}_{5}=\left[s_{1} b_{1} f_{1} g_{1} s_{1} b_{1} f_{1} g_{2} \ldots s_{2} b_{4} f_{m-}\right.$ $\left.g_{32}\right]$ (additive genetic effect). Also,

$$
\mathbf{G}=\left[\begin{array}{cccc}
\sigma_{b(s)}^{2} \cdot \mathbf{I}_{8 \times 8} & & & \\
& \sigma_{f}^{2} \cdot \mathbf{I}_{m \times m} & & \\
& & \sigma_{s \cdot f}^{2} \cdot \mathbf{I}_{2 m \times 2 m} & \\
& & \sigma_{b(s) \cdot f}^{2} \cdot \mathbf{I}_{8 m \times 8 m} & \\
& 0 & {\left[\begin{array}{cc}
\sigma_{a}^{2} & \rho \sigma_{a}^{2} \\
\rho \sigma_{a}^{2} & \sigma_{a}^{2}
\end{array}\right] \otimes \mathbf{A}_{32 m \times 32 m}}
\end{array}\right]
$$

and $\mathbf{R}=\boldsymbol{\sigma}^{2} \cdot \mathbf{I}_{64 m \times 64 m}$.

In the above, $\mathbf{A}$ is a numerator relationship matrix that models the genetic covariance among relatives, $\sigma_{a}^{2}$ is the additive genetic variance, and $\rho$ is the correlation of the additive genetic variance between the two sites (i.e., $\mathrm{G} \times \mathrm{E}$ interaction). Incorporating the relationship matrix allows for the estimation of breeding values for individual trees and parents (Dutkowski et al. 2002). $\otimes$ is the Kronecker product between two matrices.

Best linear unbiased predictions (BLUPs) of parental breeding values were evaluated, and the correlation between the predicted and true breeding value for parent (or individual) $i$ was estimated as:

$\widehat{r}_{i}=\sqrt{1-\frac{P E V_{i}}{\widehat{\sigma}_{a}^{2}}}$

where $P E V_{i}=\operatorname{var}\left(\hat{u}_{5 i}-u_{5 i}\right)$ is the prediction error variance (i.e., mean square prediction error) and $\hat{\sigma}_{a}^{2}$ is the estimated additive genetic variance (Mrode 2005).

For all mixed models (with the exception of the model for seedling survival), unknown parameters were estimated using restricted maximum likelihood (REML) using version 2 of ASReml software (Gilmour et al. 2006). Penalized quasilikelihood (PQL) was used to estimate parameters for the survival model based on binomial distribution with a logit link function.

\section{Results}

Survival at age 26 years from the seed stage was most severely affected by levels of inbreeding on both sites (Table 1), ranging from a high of $95 \%$ at North Arm for outcrossed trees to $10 \%$ for selfed trees at Langley. Combined over the two sites, the relationship between inbreeding and survival was linear (Fig. 1). Inbreeding depression in height, diameter, and tree volume at age 26 rose between half-sibs $(f=0.125)$ and fullsibs and parent-offspring trees $(f=0.25)$, then leveled off somewhat for selfed trees (Fig. 1). This is in contrast with the linear inbreeding depression observed for survival.

The analysis of covariance with height as the covariate for wood density indicated no significant interaction between height and inbreeding, suggesting the regression lines are parallel and no adjustments needed to be made for the analysis of wood density (Fig. 2, ANCOVA not shown). Wood density experienced the least inbreeding depression of all traits, averaging only $3.5 \%$ inbreeding depression for selfs across both test sites (Fig. 1, Table 1). The values obtained for wood density are close to those measured in offspring of parents of the same breeding population (Stoehr et al. 2009).

Genetic variation, expressed as family within inbreeding level, for height and diameter increased with tree age, accounting for 3.1 and $5.9 \%$ of the total variation in height at age 10 and 26 , respectively and between 0.7 and $6.2 \%$ for diameter. However, wood density at age 26 exhibited the greatest genetic variation with $19.9 \%$ (Table 2 ). Interactions of site $\times$ family within inbreeding levels were significant for all growth traits, but not for wood density (Table 2). On the two sites, individually, this trend holds as family variation in height increased from age 10 to 26 from 4.5 to $6.6 \%$ and from 5.3 to $10.8 \%$ at Langley and North Arm, respectively (data not shown).

Temporal variation in inbreeding depression is shown in Fig. 3. Initially, inbreeding depression rose in height and diameter for all inbreeding levels up to age 10 and then leveled off (Fig. 3a, b). The pattern for dbh is similar as the one observed for $P$. radiata by Wu et al. (1998b), who observed a sigmoid growth curve for dbh cross-sectional area, starting at age 4 and beginning to level off by age 8 . In contrast, inbreeding depression for survival at the lower levels of inbreeding was low up to age 10 and then increased substantially. For selfed trees, inbreeding depression followed a linear pattern to age 26. It appears that tree-to-tree competition in the closely spaced test plantations was the driving force for this 
Fig. 1 Inbreeding depression (\%) for three levels of inbreeding $(f=$ $0.125,0.25$, and 0.5 ) in five traits measured in coastal Douglas-fir at age 26 averaged on two farm-field test sites in coastal British Columbia

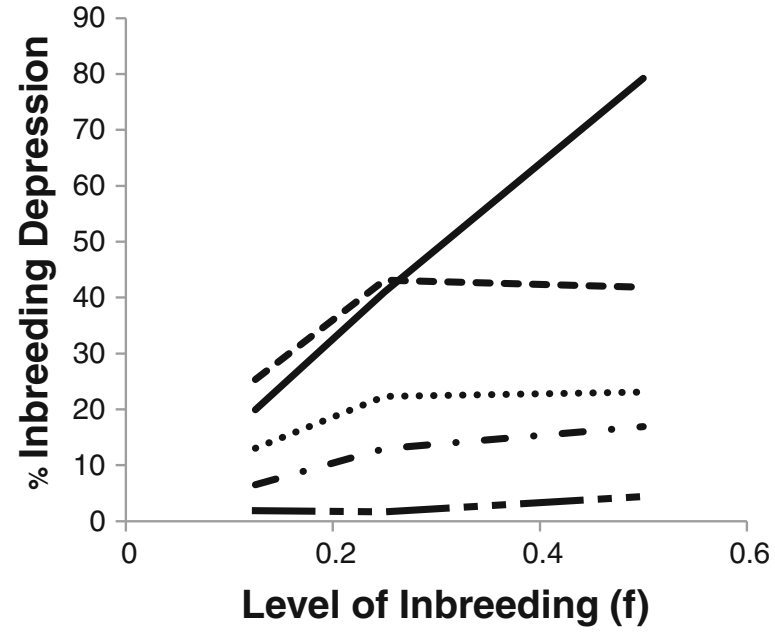

Survival

- - Tree Volume

$\mathrm{DBH}$

- - Height

-Wood Density response as ID in this trait severely increases over time, although the rate of inbreeding depression was more or less constant between age 6 and 26 (Fig. 3c).

To evaluate the response of the founder parents to various levels of inbreeding, breeding values for each level of $f$ was calculated (except for $f=0.5$ as only a few selfed trees had survived) using an individual tree model. Several founders performed well for height growth at ages 10 and 26 under all levels of inbreeding, such as clones 408 and 623 (Table 3), while parent 193 performed better with inbreeding at both ages (parent 499 performed better only at age 26). Two parents $(62,499)$ had positive BLUPs for wood density at all levels of inbreeding, while seedlings of parent 28 performed better for this trait at $f=0.125$ and $f=0.25$ in comparison to outcrossed seedlings derived from this parent. Correlations of BLUPs between the various levels of inbreeding for height and wood density are shown in Table 4 . In all traits, the correlations between $f=0$ and $f=0.25$ were higher than between $f=0$ and $f=$

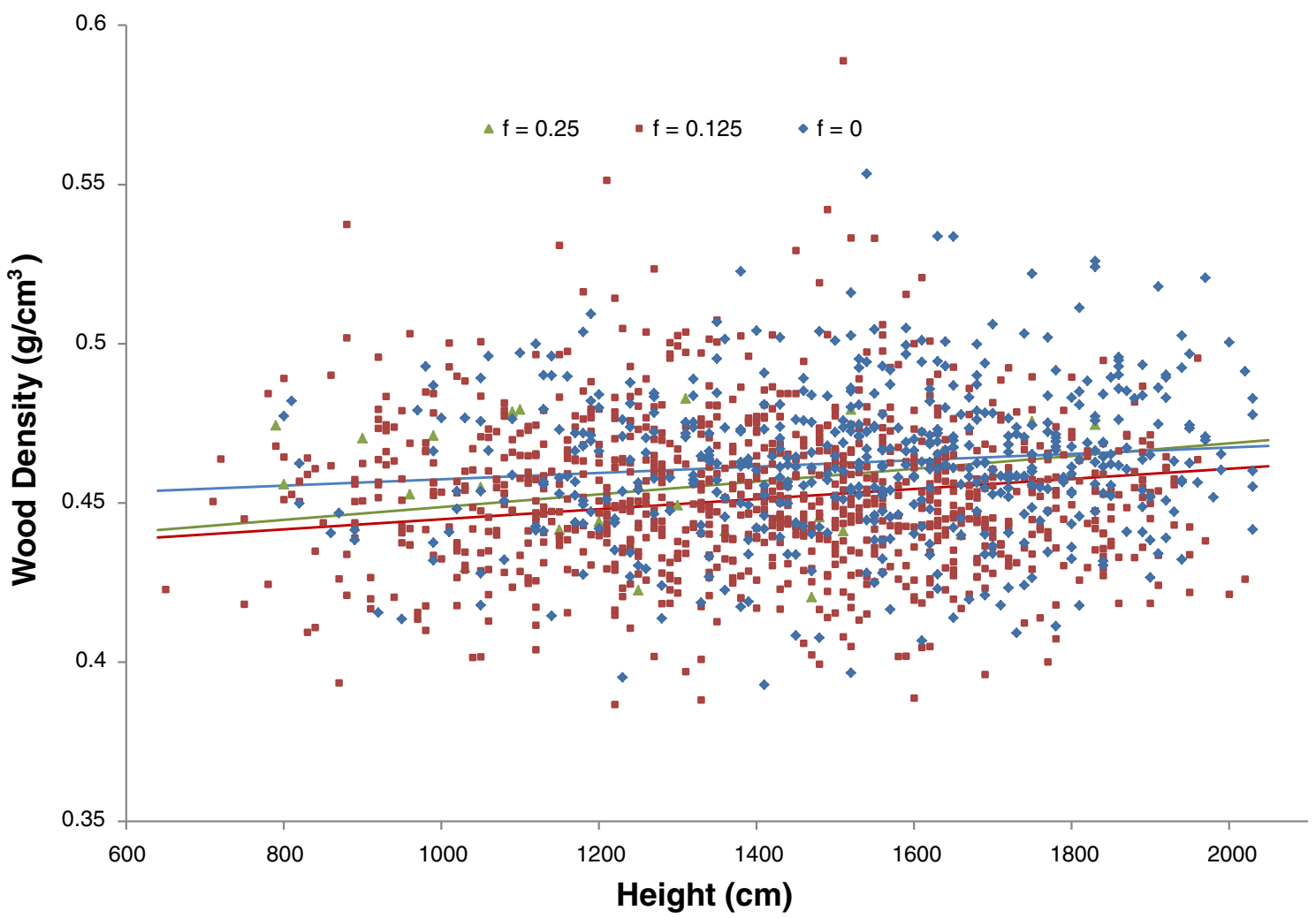

Fig. 2 Wood density vs. height at age 26 of trees at three distinct levels of inbreeding. The nearly equal slope of the regression lines indicates that height does not affect wood density at different inbreeding levels 
Table 2 Variance components and proportion of total variation for random effects and levels of significance for fixed effect for traits measured at two ages for families of four levels of inbreeding growing on two sites in southern British Columbia

\begin{tabular}{|c|c|c|c|c|c|c|c|c|c|c|}
\hline \multirow{3}{*}{ Random effects } & \multicolumn{2}{|l|}{ Height 10} & \multicolumn{2}{|c|}{ Diameter 10} & \multicolumn{2}{|c|}{ Height 26} & \multicolumn{2}{|c|}{ Diameter 26} & \multicolumn{2}{|c|}{ Wood density 26} \\
\hline & \multicolumn{10}{|c|}{ Variance component } \\
\hline & $\mathrm{VC}$ & $\%$ & $\mathrm{VC}$ & $\%$ & $\mathrm{VC}$ & $\%$ & $\mathrm{VC}$ & $\%$ & $\mathrm{VC}$ & $\%$ \\
\hline Blocks/site & 2,622 & 19.4 & 37.7 & 2.0 & 4,126 & 5.8 & 24.2 & 1.9 & 12.9 & 1.7 \\
\hline Families/IL & 426 & 3.1 & 12.6 & 0.7 & 4,182 & 5.9 & 114.9 & 9.2 & 152.6 & 19.9 \\
\hline Site $\times$ families/IL & 274 & 2.0 & 5.5 & 0.3 & 3,639 & 5.1 & 51.3 & 4.1 & 0 & 0.0 \\
\hline Blocks/site $\times$ families/IL & 1,500 & 11.1 & 24.6 & 1.3 & 6,411 & 9.0 & 35.7 & 2.9 & 0 & 0.0 \\
\hline Residual & 8,711 & 64.4 & $1,850.0$ & 95.8 & 52,852 & 74.2 & $1,024.7$ & 81.9 & 600.7 & 78.4 \\
\hline Fixed effects & \multicolumn{10}{|c|}{ Significance level } \\
\hline Site & \multicolumn{2}{|c|}{0.26} & \multicolumn{2}{|l|}{0.44} & \multicolumn{2}{|l|}{$<0.02$} & \multicolumn{2}{|l|}{$<0.001$} & \multicolumn{2}{|l|}{$<0.001$} \\
\hline $\mathrm{IL}$ & \multicolumn{2}{|l|}{$<0.001$} & \multicolumn{2}{|l|}{$<0.001$} & \multicolumn{2}{|l|}{$<0.001$} & \multicolumn{2}{|l|}{$<0.001$} & \multicolumn{2}{|l|}{0.12} \\
\hline
\end{tabular}

IL level of inbreeding $(0,0.125,0.25,0.5)$, wood density 26 wood density $\times 1,000$ at 26 years of age

0.125. Rank correlations between BLUPs between age 10 and 26 were $0.77,0.62$, and 0.80 for $f=0, f=0.125$, and $f=0.25$, respectively.

Differences in performance between full-sib and parentoffspring matings, both having an inbreeding coefficient of $f=$ 0.25 , were generally small and non-significant for growth traits and wood density (Table 5).

\section{Discussion}

Inbreeding effects for growth traits continue to increase and are highly significant at age 26 . Age is also associated with an increase in genetic variation, expressed as variation due to families within inbreeding levels, while family by site interaction remains relatively stable over time (Table 2). Survival shows the highest level of inbreeding depression of all traits assessed, with selfing causing the highest mortality and halfsib matings the least. Intuitively, one would expect that survival suffers the most from ID as it is the ultimate expression of fitness, yet Matheson et al. (1995) with slash pine (Pinus elliottii) found very little evidence of ID in survival. However, given their different experimental designs (split-plot with cross types as main plots and family subplots), competition effects may have been drastically different in comparison to the ones in our tests.

In our study, tests were established at close stand spacing levels of $1.0 \times 1.0 \mathrm{~m}$ and $1.5 \times 1.0 \mathrm{~m}$ to allow the examination of the effects of inter-tree (or stand) competition vs. inbreeding and their interaction at a relatively young age. While this close spacing is not used for commercial planting of Douglas-fir, the increased stand density accelerates competition effects allowing them to be evaluated at a younger age and in much smaller plantations relative to using normal commercial intertree spacing of 2.0 to $3.0 \mathrm{~m}$. The high stand density resulted in increasing and substantial crown competition among trees with stand age. In selfed trees, the rate of change in mortality ID from age 5 to 26 was consistent as indicated by the steady increase shown in Fig. 3. Trees with lower levels of inbreeding $(f=0.125$ and 0.25$)$ appear to have been affected by crown closure after age 10, as the rate of ID in survival increased, indicating that competition may be partially responsible for the at least some of the observed mortality. Because of this competition, slower growing trees are increasingly unable to compete for light and other resources. It is likely that the higher levels of mortality for more inbred trees is the result of slower average growth rates, causing them to be suppressed and lose vigor due to inter-tree competition. As this study is not replicated at a wide spacing where inter-tree competition would be avoided, it cannot be stated with certainty, however, that higher observed mortality levels for more inbred trees is due to interactions with competition or if these higher levels would occur in the absence of competition. However, there is evidence in our study that ID increases with environmental stress level (Fox and Reed 2010) as survival of selfed trees (and other inbreeding levels) at Langley was lower than at North Arm. At North Arm, survival of outcrossed trees was $95 \%$ while at Langley it was $65 \%$, suggesting a much more stressful environment.

Wood density showed the least ID of all traits and was statistically not different (at $\alpha=0.05$ ) among inbreeding levels. This lack of ID in wood density has also been observed in radiata pine (Wu et al. 2002). These authors hypothesized that the reason for a lack of ID in wood density could be that it is not a fitness trait that is strongly selected against under normal conditions in a growing stand of trees. However, in another important fitness trait, resistance to the near-fatal needle cast disease Dothistroma in radiata pine, ID was found to be only moderately severe (Kumar 2004). Other explanations on why wood density is not affected by inbreeding could be the potentially lower number of lethal or deleterious recessive loci and or the lack of genetic correlation between height 
Fig. 3 Time trends in inbreeding depression for height (a),

diameter (b), and survival (c) for three levels of inbreeding in coastal Douglas-fir averaged over two test sites in coastal British Columbia

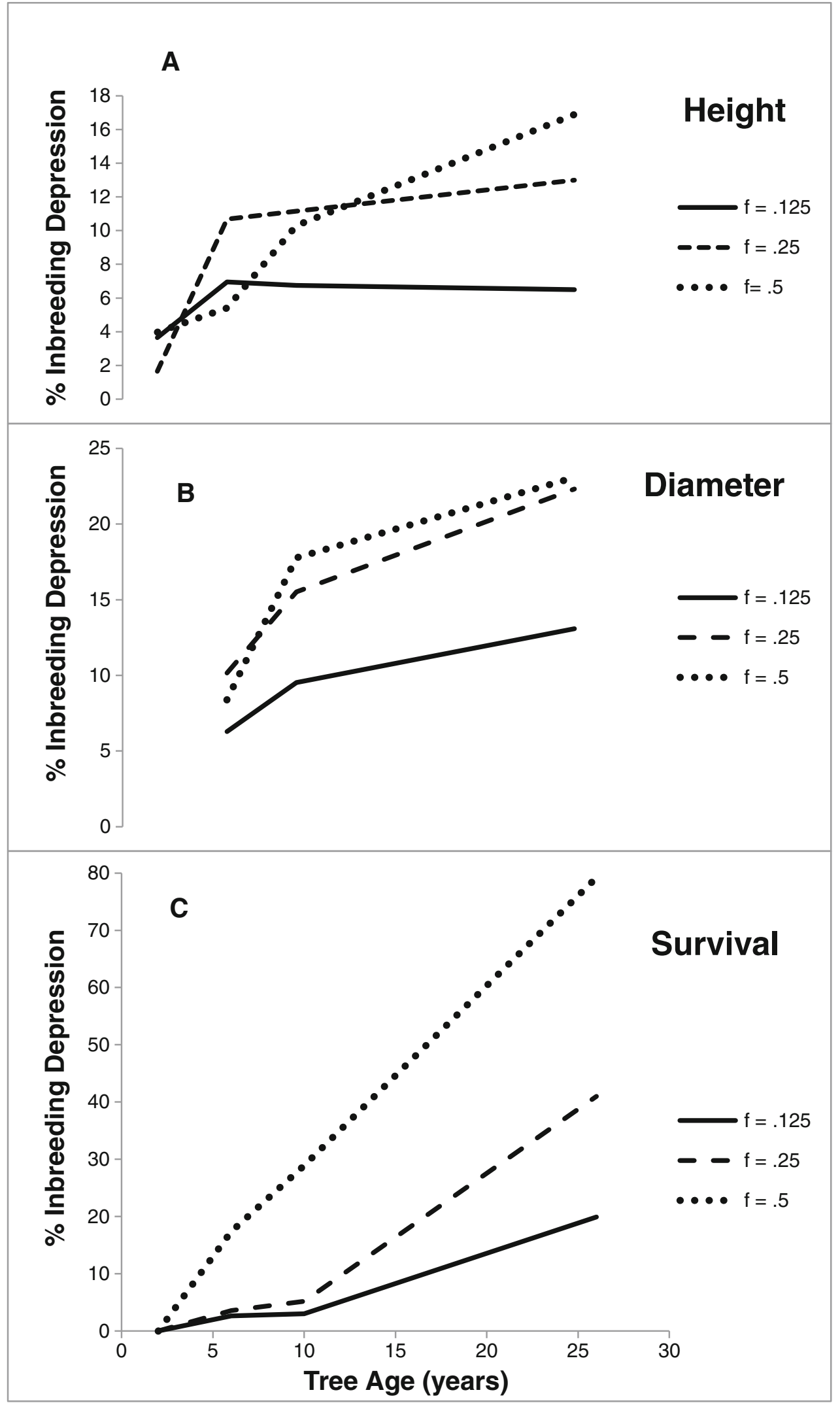

growth and wood density in radiata pine (Wu et al. 2002). Negative genetic correlations between height growth and wood density imply that slower growing trees have higher wood density. In our study, we observed a genetic correlation 
Table 3 Breeding values (BLUPs) and accuracy of prediction $(r)$ for nine founder parents calculated for three traits and three inbreeding levels across two sites

\begin{tabular}{|c|c|c|c|c|c|c|}
\hline \multirow[t]{3}{*}{ Parent } & \multicolumn{6}{|c|}{ Inbreeding } \\
\hline & \multicolumn{2}{|l|}{$f=0$} & \multicolumn{2}{|l|}{$f=0.125$} & \multicolumn{2}{|l|}{$f=0.25$} \\
\hline & BLUPs & $r$ & BLUPS & $r$ & BLUPS & $r$ \\
\hline & \multicolumn{6}{|c|}{ Height 10} \\
\hline 28 & 5.5 & 0.59 & -12.9 & 0.65 & 1.4 & 0.48 \\
\hline 33 & -7.4 & 0.60 & 4.7 & 0.65 & -7.9 & 0.51 \\
\hline 62 & 4.9 & 0.60 & 11.7 & 0.65 & -2.1 & 0.50 \\
\hline 193 & -4.5 & 0.58 & 33.9 & 0.63 & 5.2 & 0.47 \\
\hline 408 & 14.9 & 0.59 & 0.7 & 0.64 & 4.5 & 0.51 \\
\hline 448 & -3.0 & 0.60 & -3.5 & 0.65 & 0.4 & 0.49 \\
\hline 499 & -15.2 & 0.58 & -18.6 & 0.63 & 4.5 & 0.44 \\
\hline 549 & -17.5 & 0.56 & -29.3 & 0.62 & -15.4 & 0.48 \\
\hline \multirow[t]{2}{*}{623} & 22.2 & 0.59 & 13.3 & 0.62 & 9.3 & 0.45 \\
\hline & \multicolumn{6}{|c|}{ Height 26} \\
\hline 28 & -37.9 & 0.68 & -13.2 & 0.65 & -34.2 & 0.68 \\
\hline 33 & 5.2 & 0.68 & 13.3 & 0.65 & -29.8 & 0.71 \\
\hline 62 & 40.7 & 0.69 & 2.9 & 0.65 & 5.5 & 0.70 \\
\hline 193 & -37.3 & 0.68 & -25.2 & 0.63 & -3.6 & 0.68 \\
\hline 408 & 66.2 & 0.68 & -0.5 & 0.64 & 64.1 & 0.72 \\
\hline 448 & -8.1 & 0.68 & -3.1 & 0.65 & -19.6 & 0.70 \\
\hline 499 & -41.9 & 0.67 & 32.4 & 0.62 & 61.5 & 0.65 \\
\hline 549 & -50.1 & 0.66 & -7.5 & 0.62 & -101.0 & 0.69 \\
\hline \multirow[t]{2}{*}{623} & 63.0 & 0.68 & 0.7 & 0.62 & 57.1 & 0.67 \\
\hline & \multicolumn{6}{|c|}{ Wood density 26} \\
\hline 28 & -13.2 & 0.84 & 12.9 & 0.72 & 1.4 & 0.83 \\
\hline 33 & 13.3 & 0.84 & -13.2 & 0.72 & 9.8 & 0.84 \\
\hline 62 & 2.9 & 0.84 & 11.1 & 0.72 & 17.6 & 0.84 \\
\hline 193 & -25.2 & 0.86 & -23.8 & 0.71 & -28.1 & 0.83 \\
\hline 408 & -0.5 & 0.87 & -1.7 & 0.73 & -15.3 & 0.85 \\
\hline 448 & -3.1 & 0.84 & -10.8 & 0.72 & 3.2 & 0.84 \\
\hline 499 & 32.4 & 0.86 & 20.1 & 0.71 & 13.8 & 0.82 \\
\hline 549 & -7.5 & 0.86 & 1.4 & 0.71 & 0.3 & 0.84 \\
\hline 623 & 0.7 & 0.87 & 4.0 & 0.71 & -2.6 & 0.82 \\
\hline
\end{tabular}

between height at age 26 and wood density of $0.07(\mathrm{se}=0.17)$ (analysis not shown), which is in contrast to the genetic correlations in outcrossed trees ranging from -0.17 to -0.18

Table 4 Correlations of breeding values (BLUPs) for founder parents between three levels of inbreeding $(f)$ and three traits

\begin{tabular}{|c|c|c|c|c|c|c|}
\hline \multirow{2}{*}{$\begin{array}{l}\text { Trait } \\
f\end{array}$} & \multicolumn{2}{|c|}{ Height 10} & \multicolumn{2}{|c|}{ Height 26} & \multicolumn{2}{|c|}{ Wood density } \\
\hline & 0.125 & 0.25 & 0.125 & 0.25 & 0.125 & 0.25 \\
\hline 0 & 0.48 & 0.60 & 0.27 & 0.58 & 0.35 & 0.68 \\
\hline 0.125 & & 0.52 & & 0.47 & & 0.48 \\
\hline
\end{tabular}

Table 5 Differences in performance of progeny obtained via full-sib matings and parent-offspring matings

\begin{tabular}{lccc}
\hline \multicolumn{3}{l}{ Mating type } \\
\cline { 2 - 4 } & Full-sib & Parent-offspring & \% Difference \\
\hline Sample size & 555 & 240 & \\
Trait & & & \\
Height 10 (m) & 4.7 & 4.6 & 2.2 \\
Height 26 (m) & 13.4 & 13.2 & 1.5 \\
Diameter 26 (cm) & 10.1 & 10.2 & -1.0 \\
Wood density & 0.467 & 0.468 & -0.2 \\
Survival & 48.9 & 44.0 & 10.0 \\
\hline
\end{tabular}

${ }^{\mathrm{a}} \%$ Difference $=(1$-mean of parent-offspring/mean of full-sib $) * 100$

(Ukrainetz et al. 2008; El-Kassaby et al. 2011). Thus, our expectations were confirmed that only small differences exist between outcrossed and inbred trees in wood density.

In all growth traits analyzed (Table 5), there were no differences among trees arising from parent-offspring matings or full-sib matings using the family model described above (analysis not shown). Survival was analyzed as a binary variate using the "logit" link function in ASReml. Therefore, the type of mating does not influence the outcome, given the same level of inbreeding. Survival showed the largest difference, although this difference was not significant between the two groups with the same $f$-level (Table 5).

There is evidence that severity of ID and genetic load varies among parents with mixed mating systems (Restoux et al. 2012). In our study, we have observed that different parents show a range of responses to inbreeding, depending on trait and age of assessment. For example, parent 28 had a positive breeding value (bv) for height at age ten as an outcrossed parent, but negative bvs for height at age 26 for all levels of inbreeding and for wood density. Matheson et al. (1995) also observed varied responses in ID for individual families and could trace the differences back to the grandparents of the families. Wu et al. (1998a) suggested that if a tree performs well at all levels of inbreeding due to either a low number of deleterious recessive genes or due to a higher inherent level of genetic homogeneity, then, this tree would be a desired parent in advance generation breeding. In our study, parent 623 is such a genotype (Table 3 ) and indeed is a strong performing parent in the operational breeding program focusing on commercial growth and wood quality traits.

These varied responses may make progeny test analysis very unreliable when breeding populations are structured into sublines, where levels of inbreeding are accumulated within sublines. Given a certain level of inbreeding in a test family, the estimated bv of a particular parent may be far different from the true bv if the parent is used as an outcross parent. For example, the $f$-coefficient after two generations of half-sib 
mating is around 0.22 (Falconer 1989, p. 93). Given that selections are made at age 10 , the breeding value estimated for a parent after two generations of half-sib mating would only explain $25 \%$ of the bv obtained from an outcross progeny test ( $r=0.5$ between $f=0$ and $f=0.25$, Table 4). Confirmation of the "true" bv of a parent through an outcross test to evaluate general combining ability (GCA) with a common pollen mix (polymix) is therefore warranted.

The rationale to initiate this study was to see how inbred seedlings, produced in advance generation seed orchards with some level of co-ancestry among orchard parents, would affect stand timber yields at harvest (Woods and Heaman 1989). Early nursery performance showed increased seedling culling levels with higher levels of inbreeding levels (Woods et al. 2002), resulting in lower proportions of inbred trees advancing to field planting. This has the effect of reducing the average level of inbreeding in planted populations relative to inbred levels in the original seedlot (and may have led to an underestimation of ID in our study). Stand growth and yield simulations for seed orchard crops, using growth data from the trials reported here, showed that stand growth and yield in an operational setting are not affected by the relatively low occurrence of inbred seed in seedlots derived from seed orchards (Wang et al. 2004). This is because in most plantations of Douglas-fir, such as those in coastal British Columbia, planting is generally done at $3 \mathrm{~m} \times 3 \mathrm{~m}$ spacing $(1,111$ seedlings per hectare). On moderate site index sites ( $\mathrm{SI}=30$, i.e., height of top 100 trees in stand are on average $30 \mathrm{~m}$ tall at age 50), only 743 trees are expected to be harvested at age 60 (Di Luca 2013). Given these stand dynamics and given the high ID in growth, the slower growing inbred trees have a higher probability of being eliminated by inter-tree competition than noninbred trees. The results from this study support the conclusions reached by Wang et al. (2004).

From the perspective of progeny testing for the evaluation of parental bvs in an advanced generation tree breeding program with sublines to restrict inbreeding to within breeding groups, the estimation of the genetic quality of the parents may be unreliable as we have seen that different parents respond to inbreeding to differing degrees. Therefore, we recommend that breeding values should only be assigned to parents after their outcrossed progeny are assessed via GCA testing using polymix.

Acknowledgments The authors wish to say thanks to Lisa Hayton and Keith Bird for assisting in the data gathering process. Internal reviews of the manuscript were conducted by Drs. Xie, El-Kassaby and Yanchuk and by Mr. Ukrainetz.

Funding Funding for the measurements of the 26-year-old trees was provided by the Landbase Investment Strategy via the Forest Genetics Council of British Columbia.

\section{References}

Burdon RD, Russell JH (1998) Inbreeding depression in selfing experiments: statistical issues. For Genet 5:179-189

Charlesworth D, Charlesworth B (1987) Inbreeding depression and its evolutionary consequences. Ann Rev Ecol Syst 18:237-268

Charlesworth D, Willis JH (2009) The genetics of inbreeding depression. Nat Rev Genet 10:783-796

Costa e Silva J, Dutkowski GW, Gilmour AR (2001) Analysis of early tree height in forest genetic trials is enhanced by including a spatially correlated residual. Can J For Res 31:1887-1893

Di Luca MC (2013) A Table Interpolation Program for Stand Yields (TIPSY) version 4.3, 2013. Ministry of Forests, Lands and Natural Resource Operations, Forest Analysis and Inventory Branch, Victoria B.C. http://www.for.gov.bc.ca/hre/software/download.htm

Dutkowski GW, Costa e Silva J, Gilmour AR, Lopez GA (2002) Spatial analysis methods for forest genetic trials. Can J For Res 32:2201-2214

El-Kassaby YA, Mansfield S, Isik F, Stoehr M (2011) In situ wood quality assessment in Douglas-fir. Tree Genet Genom 7:553-561

Falconer DS (1989) Introduction to quantitative genetics. Longman Scientific and Technical and John Wiley and Sons Inc., New York

Ford GA (2012) Effects of inbreeding on growth and wood properties in loblolly pine. MSc thesis, North Carolina State University

Fox CW, Reed DH (2010) Inbreeding depression increases with environmental stress: an experimental study and meta-analysis. Evolution 65-1:246-258

Gilmour AR, Gogel BJ, Cullis BR, Thompson R (2006) ASReml user guide Release 2.0. VSN International Ltd, Hemel Hempstead

Kumar S (2004) Effect of selfing on various economic traits in Pinus radiata and some implications for breeding strategy. For Sci 50:571-578

Matheson AC, White TL, Powell GR (1995) Effects of inbreeding on growth, stem form and rust resistance in Pinus elliottii. Silvae Genet 44:37-46

Mrode RA (2005) Linear models for the prediction of animal breeding values, 2nd edn. CABI Publishing, Wallingford

Omule SAY, Fletcher VE, Polsson KR (1987) Total and merchantable volume equations for small coastal Douglas-fir. Canada/BC Econ. And Regional Development Agreement Rep. 10

Orr-Ewing AL (1954) Inbreeding experiments with Douglas-fir. For Chron 30:7-16

Orr-Ewing AL (1957) A cytological study of the effects of selfpollination on Pseudotsuga menziesii (Mirb.) Franco. Silva Genet 6:179-185

Orr-Ewing AL (1974) The incidence of dwarfing in inbred Douglas fir. BC Forest Service Research Note 64. Res. Div. BC Forest Service, Victoria

Orr-Ewing AL (1976) Inbreeding in Douglas fir to the $S_{3}$ generation. Silvae Genet 25:179-183

Restoux G, Huot de Longchamp P, Fady B, Klein EK (2012) Variability of individual genetic load: consequences for the detection of inbreeding depression. Genetica 140:39-51

Smith DM (1954) Maximum moisture content methods for determining specific gravity of small wood samples. USDA For. Serv., Forest Products Lab, Madison, Sen. Rep. 2014

Sorensen FC (1999) Relationship between self-fertility, allocation of growth and inbreeding depression in three coniferous species. Evolution 53:417-425

Sorensen FC, Miles RS (1974) Self-pollination effects on Douglas-fir and ponderosa pine seeds and seedlings. Silvae Genet 23:135-138

Sorensen FC, Miles RS (1982) Inbreeding depression in height, height growth, and survival of Douglas-fir, ponderosa pine and noble fir to 10 years of age. For Sci 28:283-292

Stoehr MU, Ukrainetz NK, Hayton LK, Yanchuk AD (2009) Current and future trends in juvenile wood density for coastal Douglas-fir. Can J For Res 39:1415-1419 
Ukrainetz NK, Kang K-Y, Aitken SN, Stoehr M, Mansfield SD (2008) Heritability and phenotypic and genetic correlations of coast Douglas-fir (Pseudotsuga menziesii) wood quality traits. Can J For Res 38:1536-1546

Verbeke G, Mohlenbergs G (2000) Linear mixed models for longitudinal data. Springer Verlag, New York

Vergeer P, Wagemaker N, Ouborg NJ (2012) Evidence for an epigenetic role of inbreeding depression. Biol Lett 8:798-801

Wang T, Aitken SN, Woods JH, Polsson K, Magnussen S (2004) Effects of inbreeding on coastal Douglas fir growth and yield in operational plantations: a model-based approach. Theor Appl Genet 108:1162-1171

Williams CG, Savolainen O (1996) Inbreeding depression in conifers: implications for breeding strategy. For Sci 42:102-117
Woods JH, Heaman JC (1989) Effects of different inbreeding levels on filled seed production in Douglas-fir. Can J For Res 19:54-59

Woods JH, Wang T, Aitken SN (2002) Effects of inbreeding on coastal Douglas-fir: nursery performance. Silvae Genet 51:163-170

Wu HX, Matheson AC, Spencer D (1998a) Inbreeding in Pinus radiata. I. The effect of inbreeding on growth, survival and variance. Theor Appl Genet 97:1256-1268

Wu HX, Matheson AC, Spencer D (1998b) Inbreeding in Pinus radiata II: time course of inbreeding depression and effects on growth curve. N Z J For Sci 28:123-139

Wu HX, Matheson AC, Abarquez A (2002) Inbreeding in Pinus radiata. IV: the effect of inbreeding on wood density. Ann For Sci 59:557-562 